\title{
MODERASI BERAGAMA DALAM ISLAM DAN RELEVANSINYA DENGAN KONTEKS KEINDONESIAAN
}

\author{
Ahmad Mustafidin, S.Pd.I. M.S.I. \\ Dosen Tetap di Sekolah Tinggi Agama Islam Walisembilan (SETIA WS) \\ Semarang, Mahasiswa S3 Unwahas Semarang \\ Email: riva.fidin@gmail.com
}

\begin{abstract}
The failure to have a dialogue between religious understanding and social reality in Indonesia, which is multicultural, plural, and diverse, is the root of social conflicts with religious backgrounds. The failure to dialogue understanding is experienced by hardline groups who do not want to tolerate and find it difficult to compromise with the understanding of other religions that are different. The main commitment of religious moderation to tolerance makes it the best way to deal with religious radicalism that threatens religious life itself and, in turn, affects the life of community, nation and state unity.
\end{abstract}

Keyword: Moderation of Religion, Indonesian

Abstrak

Kegagalan dalam mendialogkan pemahaman agama dengan realitas sosial di Indonesia yang multikultural, plural, dan beragam merupakan akar dari konflikkonflik sosial berlatarbelakang agama. Kegagalan mendialogkan pemahaman dialami oleh kelompok garis keras yang tidak mau mentolelir dan sulit berkompromi dengan pemahaman agama lain yang berbeda. Komitmen utama moderasi beragama terhadap toleransi menjadikannya sebagai cara terbaik untuk menghadapi radikalisme agama yang mengancam kehidupan beragama itu sendiri dan, pada gilirannya, mengimbasi kehidupan persatuan bermasyarakat, berbangsa, dan bernegara.

Kata Kunci: Moderasi Beragama, Indonesia

\section{A. PENDAHULUAN}

Indonesia termasuk negara yang besar akan tetapi kehidupan beragama pada saat ini mendapatkan sorotan dari berbagai pihak dan kalangan, baik dari dalam negeri maupun luar negeri. Adapun Semuanya ini dikarenakan sering terjadi konflik sosial yang mana berlatar belakang sebuah agama yang terus muncul ditengah-tengah masyarakat. Adapun permasalahannya diantaranya mulai dari kasus penistaan agama, perusuhan antar agama dan golongan, perusakan tempat tempat ibadah, ujaran kebencian dimana mana, bahkan mereka saling mendeskriditkan antara satu umat beragama dengan umat agama yang lain, terorisme, serta bom bunuh diri. 
Kegagalan dalam mendialogkan pemahaman agama dengan realitas sosial di Indonesia yang multikultural, plural, dan beragam merupakan akar dari konflik-konflik sosial berlatarbelakang agama. Kegagalan mendialogkan pemahaman dialami oleh kelompok garis keras yang tidak mau mentolelir dan sulit berkompromi dengan pemahaman agama lain yang berbeda. ${ }^{1}$ Kasus seperti ini mengharuskan negara memiliki cara berfikir dan bernarasi sendiri agar tidak terjebak dalam sekat ruang-ruang sosial. Lukman Hakim dalam jurnal Edy Sutrisno, menyerukan agar moderasi beragama menjadi arus utama dalam corak keberagamaan masyarakat Indonesia. Alasannya jelas dan tepat, bahwa beragama secara moderat sudah menjadi karakteristik umat beragama di Indonesia, dan lebih cocok untuk kultur masyarakat yang majemuk. Pada era sekarang beragama secara moderat tetap diperlukkan meskipun model beragama ini telah lama dipraktikkan. ${ }^{2}$

Fenomena-fenomena yang ada pada saat ini tersebut mau tidak mau semakin mempertajam sentimen bahkan memperburuk keagamaan yang ada di Indonesia saat ini. Tajamnya sentimen keagamaan dan maraknya isu beragama menjadikan bangsa ini terkotak-kotak bahkan terjadi antara golongan berdasarkan agama dan kepercayaan. Membuat rasa kekeluargaan, persatuan, kesatuan dan kerukunan antar bangsa menjadi renggang.

\section{B. PEMBAHASAN}

Kata moderasi sendiri mengandung makna tengah, tidak ekstrim ke kanan ataupun ekstrim ke kiri, jika dikaitkan dengan persoalan agama, maka moderasi itu bersikap yang tidak mengikuti arus ke kanan ataupunke kiri. ${ }^{3}$ Menurut Kementrian Agama, cara beragama hendaknya berorientasi pada aktualisasi dari pemahaman agama di jalur moderat, tidak ekstrem dan tidak berlebihan. Moderasi beragama perlu terus disampaikan kepada seluruh

1 Yunus dan Arhanuddin Salim, "Eksistensi Moderasi Islam dalam Kurikulum Pembelajaran PAI di SMA", al-Tadzkiyyah 9, no. 2, (2018): 182, diakses pada 15 September 2021, http://ejournal.radenintan.ac.id

${ }^{2}$ Edy Sutrisno, “Aktualisasi Moderasi Beragama di Lembaga Pendidikan”, Jurnal Bimas Islam 12, no. 1, (2019): 326, diakses pada 10 September 2021, http://jurnalbimasislam. kemenag.go.id.

H. Muhibbin, "Hakekat Moderasi Beragama," dalam Moderasi Beragama: Dari Indonesia Untuk Dunia, ed. Ahmala Arifin (Yogyakarta: LKiS, 2019), 105. 
lapisan masyarakat. Mengingat banyaknya konflik yang mengatasnamakan agama. Agama yang hadir untuk menjaga harkat dan martabat kemanusiaan justru disalahgunakan untuk merendahkan sesama manusia.

Menariknya, semua agama yang diakui di Indonesia mengenal ajaran moderasi beragama. Moderasi beragama dalam ajaran Kristen menjadi cara pandang untuk menengahi ekstremitas tafsir ajaran Kristen. Pada ajaran agama Hindu berkaitan dengan moderasi beragama yang terpenting adalah susila, yaitu bagaimana menjaga hubungan yang harmonis antara sesama manusia. Esensi ajaran moderasi beragama dalam agama Budha dapat dilihat dari pencerahan sang Budha. Ia mengikrarkan empat prasetya, yaitu menolak keinginan nafsu keduniawian, menolong semua makhluk, mempelajari, menghayati, dan mengamalkan Dharma, serta berusaha mencapai pencerahan sempurna. Moderasi beragama juga terdapat dalam tradisi agama Khonghucu. Umat Khonghucu yang junzi (beriman dan berbudi luhur) memandang kehidupan ini dalam kaca mata yin yang. Yin yang adalah sikap tengah, bukan sikap ekstrem. Sesuatu yang kurang sama buruknya dengan sesuatu yang lebih. Sedangkan dalam Islam sendiri terdapat konsep wasathiyah, yang memiliki persamaan makna dengan kata tawassuth (tengah tengah), i'tidal (adil), dan tawazun (berimbang). ${ }^{4}$

Dalam sejarah peradaban dan tradisi semua agama di Indonesia maupun dunia, moderasi sudah lama menjadi aspek yang menonjol. Masing-masing agama memiliki kecenderungan ajaran yang mengacu pada satu titik makna yang sama, yaitu bahwa memilih jalan tengah di antara dua kutub ekstrem dan tidak berlebih-lebihan, merupakan sikap beragama yang paling ideal. ${ }^{5}$

Karenannya, moderasi beragama perlu tempat yang tepat untuk tumbuh dan berkembang. Lembaga pendidikan merupakan tempat yang sangat tepat untuk menyemai moderasi beragama. Mengingat beberapa tahun terakhir ini dunia pendidikan tercemar oleh paham radikalisme dan terorisme. Bom di Sarinah Thamrin Jakarta, tragedi bom Mariot dan Solo yang beberapa

\footnotetext{
${ }^{4}$ Edy Sutrisno, “Aktualisasi Moderasi Beragama di Lembaga Pendidikan”, 325.

${ }^{5}$ Kementerian Agama RI, Moderasi Beragama, (Jakarta Pusat: Badan Litbang dan Diklat Kementerian Agama RI, 2019), 11.
} 
pelakunya masih aktif sebagai siswa di salah satu sekolah menjadi bukti bahwa sekolah merupakan ruang terbuka bagi penyebaran apa saja termasuk paham-paham yang mengarah pada radikal. ${ }^{6}$

Dilansir dari Maarif Institute (2011), Setara Institute (2015), dan Wahid Foundation (2016) dalam jurnal Edy Sutrisno, menunjukkan bahwa siswa maupun mahasiswa memiliki kecenderungan sikap intoleran dan radikalis yang cukup mengkhawatirkan. Gejala intoleransi dan radikalisme cenderung lebih besar pada persoalan agama dari pada persoalan etnisitas. Oleh karenannya, pengarusutamaan moderasi beragama perlu dilakukan dalam lembaga pendidikan. ${ }^{7}$

Lembaga pendidikan menjadi sarana tepat guna dalam menyebarkan sensivitas siswa pada ragam perbedaan. Lembaga pendidikan sejatinya dapat menjadi lahan tersemainya gagasan kebangsaan, menanamkan nilai-nilai multikultural, menebarkan cinta dan kasih pada manusia, serta membawa pesan agama dengan damai. ${ }^{8}$ Dalam lembaga pendidikan, Kementerian Agama mengkampanyekan moderasi beragama diantaranya melalui pendidikan agama Islam (PAI). Pendidikan agama Islam dinilai memiliki porsi penting untuk membentuk sikap moderat dalam beragama. ${ }^{9}$

Mayoritas umat beragama di Indonesia adalah Islam, dikarenkan pendidikan agama Islam secara umum memiliki tujuan untuk menumbuhkan serta meningkatkan keimanan kepada Tuhan Yang Maha Esa melalui pengetahuan, penghayatan, pengalaman, serta pengamalan peserta didik tentang agama Islam, sehingga diharapkan dapat menjadi manusia yang terus berkembang dalam hal keimanan dan ketaqwaannya terhadap Allah SWT. Serta memiliki jiwa toleran yang tinggi dan berakhlak mulia dalam kehidupan pribadi, bermasyarakat, berbangsa, dan bernegara. ${ }^{10}$

\footnotetext{
${ }^{6}$ Iskandar Agung dan Amrazi Zako, Menangkal Penyebaran Radikalisme di Sekolah, (Bogor: IPB Press, 2018), 159-160.

${ }^{7}$ Edy Sutrisno, “Aktualisasi Moderasi Beragama di Lembaga Pendidikan”, 342

${ }^{8}$ Edy Sutrisno, “Aktualisasi Moderasi Beragama di Lembaga Pendidikan”, 342

9 Zahrotul Oktaviani, "Kemenag Kampanyekan Moderasi Beragama Melalui Pendidikan", Republika.co.id, 11 Oktober, 2021, https://republika. co.id/amp/pnadw3382

10 Yunus dan Arhanuddin Salim, "Eksistensi Moderasi Islam dalam Kurikulum
} 
Wajah moderasi beragama nampak dalam hubungan harmoni antara agama (Islam, Hindu, Budha dan Kristen) dan kearifan lokal (local value) di Indonesia. Kearifan lokal ini sebagai warisan budaya Nusantara, mampu disandingkan secara sejajar sehingga antara spirit agama dan kearifan budaya berjalan seiring, tidak saling menegasikan. Menurut Zain selaku Kepala Pusat Penelitian Lektur, Khazanah Keagamaan dan Manajemen Organisasi bahwa agama dan budaya memperkuat kebangsaan dan kebhinekaan Indonesia. Ulama dan tokoh agama pun turut serta dalam memprakarsai berdirinya Indonesia dalam kepaduan dan harmonisasi agama dan budaya. Berbagai persoalan fikih ataupun tafsir kehidupan dijawab dan disatukan dengan budaya. Agama datang memahkotai budaya lokal bukan menggerus ataupun mempertentangkannya. ${ }^{11}$

Dalam Islam rujukan beragama yang paling utama al-Qur'an dan alHadist, namun fenomena menunjukkan bahwa wajah Islam sangat banyak, Islam terkadang memiliki khas sendiri-sendiri dalam praktek dan amaliah keagamaan. Tampaknya perbedaan itu sudah menjadi kewajaran, sunatullah, dan bahkan suatu rahmat. ${ }^{12}$ Quraish Shihab mengatakan bahwa: "Keanekaragaman dalam kehidupan merupakan keniscahyaan yang dikehendaki Allah. Termasuk dalam hal ini perbedaan dan keanekaragaman pendapat dalam bidang ilmiah, bahkan keanekaragaman tanggapan manusia menyangkut kebenaran kitab-kitab suci, penafsiran kandungannya serta untuk pengalamannya". 13

Yang menjadi permasalahan adalah dapatkah dari yang berbeda tersebut untuk saling menghormati, tidak saling menyalahkan, tidak meyatakan paling benar sendiri, dan besedia bedialog sehingga tercermin bahwa perbedaan itu benarbenar rahmat. Jika ini yang dijadikan pijakan dalam beramal dan

\footnotetext{
Pembelajaran PAI di SMA", 185.

${ }_{11}$ Siswayanti, Novita. Menguatkan NKRI dengan Moderasi Beragama. Diunduh dari https://balitbangdiklat.kemenag.go.id/berita/menguatkan-nkridengan-moderasi-beragama, pada tanggal 10 Oktober 2021. Hal 1

${ }_{12}$ Sabri Mide, "Ummatan Wasatan dalam al-Qur'an", Skripsi, Fakultas Ushuluddin, Filsafat dan Politik UIN Alaudin Makassar, (2014), 2

${ }^{13}$ M. Quraish Shihab, Membumikan al-Qur'an. Jilid 2, (Jakarta: Lentera Hati , 2010), 23.
} 
beragama, maka inilah sebenarnya makna konsep "Islam moderat". Artinya siapa pun orangnya dalam beragama dapat bersikap sebagaimana kriteria tersebut, maka dapat disebut dengan Islam yang moderat. ${ }^{14}$

Islam moderat dapat merujuk kepada praktek Islam yang dilakukan oleh Nabi Muhamammad SAW dan para sahabatnya, khususnya Al-Khulafa' alRasyidin, sedangkan dalam konteks Indonesia dapat merujuk kepada para penyebar Islam yang terkenal dengan sebutan Walisongo. Artinya Islam di harapkan dapat menjadi bagian dan solusi dari persoalan bangsa, agama dan negara, maupun persoalan yang global saat ini. Krisis dunia internasional saat ini sudah sedemikian komplek sehingga Islam dituntut dapat turut andil di dalamnya, inilah yang menjadi tanggung jawab agar Islam sebagai ajaran agama yang ramah dan menjadi rahmat di tengah konflik. ${ }^{15}$

Jadi jelas bahwa Islam adalah rahmat bagi umat manusia yang telah dibawa oleh Rasulullah saw sebagai risalah, sebagaimana di jelaskan dalam Q.S. Al-Anbiya/21: 107

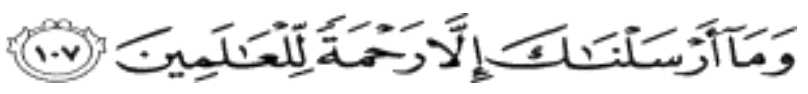

Artinya: Dan kami tidak mengutus engkau (Muhammad) melainkan (menjadi) Rahmat bagi seluruh Alam. ${ }^{16}$

Berdasarkan ayat di atas maka dapat disimpulkan bahwa seluruh umat muslim dan muslimat yang ada pada saat ini harus benar-benar memahami dan melaksanakan bahwa Islam adalah Agama Allah, oleh karena itu setiap umat Islam memikul tanggung jawab untuk memperjuangkan dan mendakwahkannya. Jadi hendaknya Islam menjadi program hidup untuk menerapkan menjadi akidah seluruh makhluk (manusia), dimana menjadikan hukum dalam pergaulan hidup dan menjadi cara hidup bagi manusia. Dalam al-Qur'an telah disebutkan bahwa Allah menjanjikan umat Islam menjadi

\footnotetext{
${ }^{14}$ Rais, M. A, Cakraawala Islam. (Bandung: 1991), 20.

15 Sabri Mide, “Ummatan Wasatan dalam al-Qur'an”, Skripsi, Fakultas Ushuluddin, Filsafat dan Politik UIN Alaudin Makassar, (2014), 2

${ }^{16}$ Depag
} 
umat terbaik, umat pilihan yang terbaik dan umat yang adil.

Islam yang seharusnya adalah agama yang adil, ramah, berperadaban tinggi dan berada di barisan paling depan. Namun yang dapat ditemui hari ini masih ada wajah Islam yang sebaliknya. ${ }^{17}$ Permasalahan yang mendasar tentang pemahaman terhadap ajaran Islam, yaitu adanya perbedaan dalam beragama dan bermadzhab, Islam itu satu, tetapi cara memahaminya yang beragam. Hal ini memunculkan istilah-istilah atau lebel dalam Islam itu sendiri. Misalnya kelompok radikal dan kelompok liberal. ${ }^{18}$

Kecenderungan radikalisme dalam Islam sangat ekstrim dan ketat dalam memahami hukum-hukum agama (Islam) dan mencoba memaksakan cara tersebut dengan menggunakan kekerasan di tengah masyarakat Muslim. Khususnya di Indonesia terdapat beberapa kelompok pemikiran dan gerakan Islam yang sering kali disebut sebagai kelompok radikal, di antara kelompok tersebut adalah mereka yang bergabung dalam jamaah Salafi Wahabi, Negara Islam Indonesia (NII), Hisbut Tahrir Indonesia (HTI), Majelis Mujahidin Indonesia (MMI), dan Front Pemuda Islam Surakarta (FPIS). ${ }^{19}$

Salafi Wahabi merupakan kelompok yang cenderung berkeinginan untuk melakukan verifikasi dengan cara melaksanakan ajaran Islam sesuai dengan kehidupan zaman Nabi dan Khulafa'urrasyidin. NII dan HTI merupakan organisasi yang fundamentalis-radikalis, karena keduanya tidak mengakui sendi-sendi negara non khilafah yang dianggap sekuler karena berdasarkan hukum buatan manusia. Adapun MMI dengan tokoh sentralnya Abu Bakar Ba'asyir dianggap mempunyai hubungan dengan Jama'ah Islamiyah yang juga disinyalir sebagai organisasi teroris oleh PBB. FPIS adalah organisasi yang memiliki kegiatan yang mempunyai kegiatan yang intens di kalangan anakanak muda Surakarta sebagai media untuk merespon problematika sosial yang

\footnotetext{
${ }^{17}$ Nor Elysa Rahmawati, 2010 "Penafsiran Muhammad Talibi tentang Ummatan Wasatan dalam alQur'an", 5.

18 Andi Aderus Banua, "Kontruksi Islam Moderat: Menguap Prinsip Rasionalitas, Humanitas, dan Universitas Islam", Jurnal. Cet, I, (Makassar: ICATT Press, 2012), 5

${ }^{19}$ H. Afadlal, "Islam dan Radikalisme di Indonesia", Jurnal. Cet. I, (Jakarta: LIPI Press, 2005), 104-
} 
ada di daerah tersebut. ${ }^{20}$

Kelompok radikal di atas menyuarakan gagasan dalam masalah penerapan syariat Islam atau mendirikan negara Islam. Upaya mereka dalam mendirikan Negara Islam yang secara keseluruhan menginginkan pemberlakuan hukum Islam secara leterlek. Sedangkan liberalisme justru sebaliknya, bisa dilihat pada sikap longgar secara ekstrim dalam kehidupan beragama dan tunduk pada perilaku dan pemikiran yang asing bila dlihat dari pertumbuhan tradisi Islam. ${ }^{21}$

Islam adalah agama yang Moderat dalam pengertian tidak mengajarkan sikap ekstrim kanan maupun kiri dalam berbagai aspeknya, pengertian ini didasarkan atas pernyataan dalam salah satu ayat al-Qur'an yang memberikan tuntunan hidup kepada umat Islam. sebagaimana dijelaskan dalam QS. AlBaqarah: 143, yang artinya: "Dan demikian (pula) Kami menjadikan kamu (umat Islam) ummatan wasathan (umat yang adil dan pilihan) agar kamu menjadi saksi atas (perbuatan manusia) dan agar Rasul (Muhammad) menjadi saksi atas (perbuatan) kamu." Jadi, dalam konteks keindonesiaan yang dimaksud dengan "moderat" yaitu suatu pandangan pemikiran yang tidak membenarkan dan menolak terjadinya kekerasan atasnama negara, seperti kasus terorisme yang disebut sebagian kalangan sebagai aksi jihad, kasus terorisme dalam beberapa tahun ini menjadi peristiwa yang sedang gencar dan marak-maraknya. ${ }^{22}$

Di sisi lain Islam mengajarkan untuk bersikap moderat sebagaimana yang telah dijelaskan di atas, tetapi disisi lain muncul pula pemahaman yang dangkal dalam berislam, sehingga dengan perkembangan zaman sekarang ini beberapa kasus kelompok muslim yang sudah tidak nampak lagi wajah Islam yang Moderat. Maka dari itu perlu dikaji pula tafsir al-Qur'an yang sesuai dengan pemahaman salaf sekaligus relevan dengan konteks kekinian. Para mufasir yang membahas mengenai Moderasi Islam dalam kitab tafsirnya,

\footnotetext{
${ }^{20}$ Afadlal dkk, "Islam dan Radikalisme di Indonesia", 107.

${ }^{21}$ Afadlal dkk, "Islam dan Radikalisme di Indonesia", 125.

${ }^{22}$ Nor Elysa Rahmawati,2010 "Penafsiran Muhammad Talibi tentang Ummatan Wasatan dalam al-Qur'an", 6.
} 
antara lain salah satu mufasir yang membahas ayat-ayat Wasathiyah adalah Moh. Emon Hasim, beliau dikategorikan sebagai mufassir kontemporer karena kitab tafsirnya ditulis mulai dari tahun 1989, kitab Tafsir Ayat Suci Lenyepaneun yang terdiri dari 30 jilid beliau menulis dengan menggunakan bahasa Sunda beraksara Roman yang orisinal. ${ }^{23}$

Sabri Mide (2014) dalam sebuah jurnal penelitian yang berjudul: "Ummatan Wasatan dalam al-Qur'an (Kajian Tafsir Tahlili dalam Q.S.alBaqarah/2: 168). Undergraduate (S1) thesis, Universitas Islam Negeri Alauddin Makassar, menjelaskan 1) Kata ummat diartikan sebagai para penganut atau pengikut suatu agama, dan pengertian wasatan adalah jalan tengah atau moderat. Maka dari itu, ummatan wasatan diartikan sebagai pengikut agama yang mengambil jalan tengah atau penganut prinsip moderat. 2) Ummatan wasatan dalam penafsiran Q.S. al-Baqarah/2: 143 menjelaskan bahwa ummatan wasatan adalah umat Islam yang benar-benar mengikuti ajaran Rasulullah saw. sebagaimana apa yang telah diajarkan oleh beliau. Yaitu dengan menjadi umat yang wasat, dalam artian menjadi umat yang adil dan seimbang dalam berbagai hal, baik dari segi syariah maupun muamalah, sehingga umat Islam tersebut dapat mencapai hablun minallah dan hablun minannas. 3) Ummatan wasatan merupakan konsep yang dapat menciptakan keharmonisan dalam kehidupan, karena dapat menyentuh segala aspek yang dihadapi oleh manusia, dan menawarkan prinsip-prinsip persatuan dengan berdalih pada al-Qur'an sebagai kitab terbuka, mengedepankan keadilan, kesetaraan, toleransi, kemanusiaan, pembebasan, pluralisme, sensitifitas gender, serta nondis kriminatif. Ummatan wasatan diharapkan dapat menjadi solusi dalam kehidupan manusia meliputi aspek akidah, aspek syariah, aspek tafsir, aspek pemikiran Islam, aspek tasawuf, aspek dakwah, dan bebagai aspek lainnya. Sehingga ini dianggap urgen untuk menciptakan persatuan dan kesatuan dalam beragama, baik dari sisi internal maupun dari sisi eksternal.

${ }^{23}$ Jajang A Rohmana, Sejarah Tafsir al-Qur’an di Tatar Sunda, (Bandung; Mujahid Press; 2017 Cet. II) 161 


\section{Kesimpulan}

Moderasi beragama termasuk salah satu usaha kreatif dan inovatif untuk mengembangkan suatu sikap keberagamaanyang ada pada saat ini dimana di tengah berbagai desakan ketegangan dari beberapa pihak seperti antara klaim kebenaran absolut dan subjektivitas, antara interpretasi literal dan penolakan yang arogan atas ajaran agama, juga antara radikalisme dan sekularisme. Komitmen utama moderasi beragama terhadap toleransi menjadikannya sebagai cara terbaik untuk menghadapi radikalisme agama yang mengancam kehidupan beragama itu sendiri dan, pada gilirannya, mengimbasi kehidupan persatuan bermasyarakat, berbangsa, dan bernegara.

\section{Daftar Pustaka}

Andi Aderus Banua, "Kontruksi Islam Moderat: Menguap Prinsip Rasionalitas, Humanitas, dan Universitas Islam”, Jurnal. Cet, I, (Makassar: ICATT Press, 2012).

H. Afadlal, "Islam dan Radikalisme di Indonesia", Jurnal. Cet. I, (Jakarta: LIPI Press, 2005).

Iskandar Agung dan Amrazi Zako, Menangkal Penyebaran Radikalisme di Sekolah, (Bogor: IPB Press, 2018).

Jajang A Rohmana, Sejarah Tafsir al-Qur'an di Tatar Sunda, (Bandung; Mujahid Press; 2017 Cet. II).

Kementerian Agama RI, Moderasi Beragama, (Jakarta Pusat: Badan Litbang dan Diklat Kementerian Agama RI, 2019).

M. Quraish Shihab, Membumikan al-Qur'an. Jilid 2, (Jakarta: Lentera Hati , 2010), 23.

Mide, S. (2014). Ummatan Wasatan dalam al-Qur'an (Kajian Tafsir Tahlili) dalam QS al-Baqarah/2: 168 (Doctoral dissertation, Universitas Islam Negeri Alauddin Makassar).

Rahmawati, N. E. (2014). Penafsiran Muhammad Talibi tentang Ummatan Wasațan dalam al-Qur'an. Rais, M. A, Cakraawala Islam. (Bandung: 1991).

Siswayanti, Novita. Menguatkan NKRI dengan Moderasi Beragama. Diunduh dari https://balitbangdiklat.kemenag.go.id/berita/menguatkan-nkridenganmoderasi-beragama, pada tanggal 10 Oktober 2021.

Sutrisno, E. (2019). Aktualisasi Moderasi Beragama di Lembaga Pendidikan. Jurnal Bimas Islam, 12(2), 323-348. H. Muhibbin, "Hakekat Moderasi 
Jurnal Pendidikan Agama Islam Universitas Wahid Hasyim

Beragama," dalam Moderasi Beragama: Dari Indonesia Untuk Dunia, ed. Ahmala Arifin (Yogyakarta: LKiS, 2019).

Yunus, Y., \& Salim, A. (2018). Eksistensi Moderasi Islam dalam Kurikulum Pembelajaran PAI di SMA. Al-Tadzkiyyah: Jurnal Pendidikan Islam, 9(2), 181-194.

Zahrotul Oktaviani, "Kemenag Kampanyekan Moderasi Beragama Melalui Pendidikan", Republika.co.id, 11 Oktober, 2021, https://republika. co.id/amp/pnadw3382. 